\title{
Developing Multi-grade Classes using SWOT Analysis
}

\author{
Sahar Moeini \\ Narges Moradian \\ Pouran Khoroshi \\ B.A student of educational sciences, Fatima Al-Zahra(S) Campus, Farhangian University of Isfahan \\ B.A student of educational sciences, Fatima Al-Zahra(S) Campus, Farhangian University of Isfahan \\ Professor of Fatima Al-Zahra(S) Campus, Farhangian University of Isfahan
}

Doi:10.5901/mjss.2016.v7n4s2p197

\begin{abstract}
With the advent of certain social, economic and cultural conditions, the educational system has had to accede to multi-grade classes. The aim of this study is to examine multi-grade classes with SWOT Approach in order to strengthen and develop these classes. For this purpose, we analyzed the opportunities, threats, strengths and weaknesses of Multi-grade classes. The findings of this study showed that unlike the special position of multi-grade classes, which often causes teachers to have negative attitude towards these classes, attention to the strengths of these classes will provide appropriate opportunities in the curriculum.
\end{abstract}

Keywords: multi-grade classes, pathology, opportunities and threats, strengths and weaknesses

\section{Introduction}

Investigations of the factors affecting progress and development in advanced societies show that all these countries have a good-quality system of education, manifesting itself in educating people needed for sustainable development projects; that is, committed experts with holistic, creative, and participatory features (Moosaei, Ahmadzadeh, 2009).

By sustainable development is meant the kind of development used for human survival and well-being as well as the creation of an interaction between man and the environment, present and future, man and nature, justice and welfare for current and future generations. In other words, sustainable development seeks to meet the needs of the present generation without harming the resources and the ability of future generations, and since efforts for all-round development in all aspects are considered among the sustainability parameters (Zahedi, Najafi, 2005), multi-grade schools are developed in order to educate the school-age children in various educational courses as well as the dropouts, which will later make up the illiterate or low-literate groups of the country and create serious problems for societies. In this regard, multi-grade classes are held in order to help reduce such problems (Babadi Akashe, Sharif, Jamshidian, 2010).

With a little investigation about the history of education, one can find that multi-grade classes date back to the beginning of group education. The main reason for the multi-grade classes is the lower-than-standard number of students in a particular grade in a school. The standard number of students, which results in the formation of classes for each grade is usually determined and communicated by the educational system. Multi-grade classes, where a teacher teaches in several grades, is an effective way of increasing the access of the children of rural areas to education. The project not only solves the issue of the low-number classes' being uneconomical, it also completes the educational grades (Lockheed, Adrian, translated by Sajadieh, 1992).

Today, all formal educational systems are organized based on age and educational grades. This (grade-based) organizing is into either single-grade or multi-grade classes. (Little, 2001). One of the ideals is single-grade classes; classes where a teacher teaches to a group of students in one grade who are somewhat similar to one another in terms of age and ability (Mortazavizadeh, 2015). But there are some special circumstances, in which teachers should guide the teaching-learning process in small or multi-grade classes. Although these classes are not welcomed by teachers and educational systems, it is necessary and reasonable to have them in certain circumstances. However, when it is necessary and reasonable (Coskuna, Metinb, 2011). The results of the study done by Beihammera about multi-grade teaching, as quoted by Kornish, indicate that this educational approach is increasing in both developing and developed 
countries (Beihammera, E. K., Hascherb, 2015).

The studies conducted in this respect suggest that the development of schools with multi-grade classrooms has two basic reasons: 1. Philosophic, 2. administrative considerations. Philosophically, these classes are developed to improve students' social and cognitive growth and to reduce their anti-social behavior. On the other hand, these classes are developed due to administrative reasons such as the declined student population, administrative - financial needs, geographical location, etc. and they are used as a tool to serve the disadvantaged people and as centers to create social awareness, economic development and educational reform. Accordingly, one of the effective measures for the revitalization of the primary school network to allow a greater number of students' access to educational centers is to develop multi-grade classes (Aghazadeh, Fazli, 2005).

In Iran, multi-grade classes are not regarded as an independent educational system and do not have their own special teachers and textbooks, but what has necessitated the development of such classes is the small number of students in rural areas due to the rural - to - urban migration, the reduced population growth, the existence of ethnic prejudice, the use of children in agriculture and animal husbandry, scattered villages, lack of experienced teachers in rural areas, the increased rate of grade repetitions (failure), the impossibility of sending female teachers to remote schools and thus the girl students' not being attracted to the schools and the reduced student population (Samadian, 2006).

Therefore, this article is intended to focus on the advantages, opportunities, threats, and strengths and weaknesses of multi-grade classes for the further and better development of these classes.

\section{Pathology of Multi-grade Classes Based on SWOT Analysis}

Today, the progress and development of organizations and institutions depends on the development of the human resources' knowledge, skills, behaviors and insights. Therefore, most of the leading organizations have increasingly focused on human resource development (Molaei Harandi, Jafari Harandi, 2012).

The SWOT analysis is a strategic planning tool used to evaluate an organization's internal and external status. The four letters in SWOT stand for strengths, weaknesses, opportunities and threats. This method is generally used for analyzing the status of organizations in addition to the strategic planning. In fact, this analysis should be considered as an efficient tool for identifying the environmental conditions and the internal capabilities of organizations (the free encyclopedia of Wikipedia). In this regard, the development and strengthening of multi-grade classes is also included in opportunities, threats, strengths and weaknesses, which will subsequently be discussed.

\section{Opportunities}

Various factors can build opportunities and those opportunities for an organization and these opportunities affect the output and outcome of institutions or organizations (the FMI Group, 2013).

The age groups' benefiting from the educational resources and facilities and their education in schools in proportion to the population of each area is referred to as educational opportunities (Ghasemi, 2013).

Based on the above-mentioned points, creating schools with multi-grade classes provides an appropriate opportunity for students to be engaged in learning.

Now we deal with the opportunity-creating management and teaching strategy that should be used by teachers in the classroom. Multi-grade class teachers are required to design integrated curricula; In fact, teachers have to consider different age groups of students in the educational design. For this purpose, they should collect bunch of different educational materials in different grades and then integrate or combine them to prepare a comprehensive instructional design in order to advance the courses in parallel and simultaneously (Smith, Beihammer, Raggl, 2015).

Although students are taught with a parallel design, a special measurement is considered for each student due to age and mental differences. Measurement in this type of classes creates an environment where students are led from individualism into group activities and cooperation with one another. Moreover, based on structuralism, the teacher plays the role of facilitating the learning process. (S. J., 1994).

The multi-grade classes' teachers should not only consider the students' individual differences, but they also should allow the students to progress in proportion to their developmental level; In addition, unlike the conventional classrooms where students are composed to compete with one another, the students of multi-grade classes rarely have sense of competition due to differences in their level of achievement and different expectations among them. This is because students in these classes spend more than a year in the classrooms, strengthen their social relationships with 
their classmates and teachers, and as a result, they show further growth when schools are developed by designing more appropriate educational programs (Taherizadeh, Mosapour, 2014).

Many multi-grade schools may be geographically located in a remote spot, causing the multi-grade teachers who often have multiple responsibilities to feel isolated and deprived of the help made by the educational system, although this problem can itself be converted to a valuable opportunity. For example, teachers can call for the support of the local community to improve the school environment and programs and take advantage of the suggestions made by indigenous people in so as to improve education (UNESCO, 2015).

\section{Threats}

Another part of the SWOT process relates to external factors that adversely affect the structure of a system and is regarded as a threat (FMI Group, 2013).

Teachers who are busy teaching in schools in rural areas feel less responsible than those teaching in single-grade schools in urban areas as they assume that the parents of children in multi-grade classes in rural areas are less interested in the economic status of their children and they do not know what demand to ask of the teachers due to their low literacy (Remello, 2003).

Multi-grade teachers are responsible for designing a wide range of different educational activities for students of different grades and have to plan and manage in order to conduct and engage students of different grades in learning during the school hours so that they can create dynamic and engaging classrooms (UNESCO, 2015). Since most of the teachers sent to multi-grade schools have low professional qualifications, this leads to the reduced educational quality in such schools, because teachers with more professional qualifications try harder to make use of the instructional strategies and facilitate learning through active teaching methods. These teachers focus on expressing significant experiences and increasing the students' ability to think and analyze and try to prepare for students an educational design based on engaging methods. But teachers with lower levels of education and professional qualifications focus solely on reading and writing skills as well as the basic math skills, and when this teaching and class management method is associated with negative attitudes toward the multi-grade classes, the learning objectives, skills and attitudes considered in the educational content will not be fulfilled (Remello, 2003).

\section{Strengths}

Strengths are factors that indicate a positive performance and increase the value and benefits of an organization (The FMI Group, 2013).

Learning in multi-grade classes has not only a formal aspect, but also informal and casual aspects. Teachers must consider this point in their teaching. This means that they should sometimes consider in their teaching the local and indigenous issues not covered in their textbooks (Haji Eshaq, 2004).

The studies conducted on the effectiveness of teaching in multi-grade classes indicate that students will achieve equal or even better results than single-grade classes if things are done properly. The findings have shown that the obtained data confirm the multi-grade classes as a success in terms of scientific development, and consider such classes as an effective alternative to single-grade classes, and when it comes to their impact on student performance, it must also be said that the organization of multi-grade classes appear much stronger than that of single-grade classes (Wallace, Mathot. Translated by Zarafshan, 2005).

The results of the study carried out by Berry showed that although the more successful students' achievement in single-grade classes furthers along with their academic achievements, weak students in multi-grade classes have had more significant achievement than weak students in single-grade classes. The results of this study also showed that since students in multi-grade classes are exposed to teamwork more than those in single-grade classes, they have achieved more achievement than students of single-grade classes in the English Language and math courses (Berry, 2001). For example, when the first-grade students attend a multi-grade class for the first time, they get help from both the teachers and the older students. Sometimes, these students are older than their brothers and sisters. With the passage of time, they learn to rely on themselves and can meet mast of their needs by learning from the behavior of other students. Elder students like to help the new learners to learn cooperation. Therefore, students in multi-grade schools learn the two roles of leadership and followership, so that younger students are put under the support, leadership and supervision of the students of higher grades who play the role of co-teachers (successors), and on the other hand younger students institutionalize the sense of respect and appreciation toward the older. This helps increase confidence and the power of 
leadership in the co-teachers (Mekosana, translated by Aghazadeh, 2007). The lower children who learn fast can reach the learners of higher grades. Older, faster or more experienced students can teach the younger, slower and less experienced ones. As a result, they will learn better.

\section{Weaknesses}

Weaknesses are factors that create barriers to the growth and progress of organizations and lower their value and status (MFI Group, 2013).

One of the challenges facing teachers in multi-grade classes is how to get together students of different grades, as it takes longer and teachers may be short of time to manage and control students with different ages (Navab, Rahimbeig, 2011). The research evidence and the findings of the studies related to this issue have shown that teachers' lack of experience and knowledge about the teaching methods and planning for these classes, the age differences among these students and conflicts among their families.

The smallness of the educational environment of these classrooms, lack of appropriate instructional equipment in the classrooms, the teachers' dealing with other affairs and functions in these schools such as management, office affairs and the teachers' lack of possibility to pay individual attention to students in these classrooms are the most important issues that have brought about great challenges for the management of these classes (Azizi, Hossein Panahi, 2013).

Another research showed that from the perspective of teachers and administrators of multi-grade classes and schools, the factors that affect the teaching process and class management are related to classroom and school facilities and educational activities, some of which are the number of the grades of each class, the number of students of each grade, aesthetic considerations of the school environment, teaching the contents common to all grades during one session, sameness of the curriculum content, the release of a quarterly magazine special to multi-grade classes, having authority and freedom of action in programs to increase the students' academic achievement, formulating the registry booklet of descriptive indicators and special portfolio for multi-grade students, scarcity of educational aid tools, lack of access to new educational resources (books, the Internet, ...), inadequate per capita, access to the Internet and computer applications (Cheshnasar, Cheshnasar, 2015).

These findings are consistent with those of Little (2008) in teaching and learning in multi-grade classes, according to which the educational problems of Multi-grade classes arise from the following factors: improper management of time in multi-grade classes, disuse of the curriculum as a guide for teaching in Multi-grade classes, improper control of multigrade classes, lack of equipment used to facilitate learning, teachers' lack of knowledge of how to deal with slow-minded students in multi-grade classes, the curriculum not commensurate with the conditions of multi-grade classes, the large number and high volume of textbooks, and having no lesson plan (Little, 2008).

The results of this survey also showed that the shortage of time in multi-grade classes is the main obstacle for the implementation of descriptive evaluation. Implementation of descriptive evaluation is more difficult in multi-grade classes than in single-grade ones due to the presence of eligible and non-eligible students under the descriptive program, and requires the teachers' following proper procedures and practices. It is better that the teacher use descriptive feedbacks for all students instead of scores during the school year and scores be included in students' records at the end of the year for those students not under the descriptive program. In order to complete the portfolio and inserting the work of students in them, it is better to use students not included in the descriptive assessment program. (Raf'ati, Khavari, Sahebekhtiari, 2014).

\section{Conclusion}

Multi-grade classes are a special educational opportunity with two or more groups of students with different abilities and educational grades. There are different views in different societies regarding the why, how, and type of and design of such classes in different societies. Some have regarded these classes as among the problems with the educational system, which should be eliminated, while others consider them to be an opportunity for educational systems.

What this study showed using SWOT analysis in relation to the status of multi-grade classes was that the benefits and opportunities provided by multi-grade classes are not fewer than those provided by single-grade classes, and that multi-grade classes should not be considered a separate part of the education system due to the need for such classes. Therefore, it is better to provide a new insight about such classes than to change the educational system. In other words, one can change the threats and weaknesses of such classes into opportunities and benefits that can ensure good-quality education for students. For example, there arise many problems for teaching in multi-grade classes due to the existence 
of several different grades in one classroom and different textbooks and their immense size. Therefore, the courses with similar concepts can be taught simultaneously in such classes. Since there are many similar concepts and materials in textbooks, these concepts can be taught simultaneously for different grades and the students of higher grades can be used to help those of lower grades.

Considering the fact that multi-grade classes are used in some countries as an appropriate educational strategy, so the multi-grade classes in the educational systems of such countries is the choice between access to education or deprivation of it. The existence of multi-grade classes not only solves the problem of the low-number classes' being uneconomical, but also completes the educational grades. In countries that have had successful experiences of multigrade classes, the students have benefited from self-regulated learning skills in addition to academic achievement.

Learning in multi-grade classes has not only a formal aspect, but it also has informal and casual aspects. In addition, in these classes, the whole child is of particular importance. Such an atmosphere provides a great opportunity to meet all the needs of children and make them known in the society.

It is therefore essential that multi-grade classes be considered special classes; that is, a special teacher with special ability, special organizing and programming, educational content with the features specific to multi-grade classes, a suitable and diverse learning environment, specific methods of teaching, specific evaluation, special classroom management for students with special circumstances - organizing the program in such a way that it is adaptable with the conditions and students of such classes.

\section{References}

Aghazadeh, M.; Fazli, R. (2005). A Guide for Teaching in Multi-grade Classes, Tehran: Ayizh Publication.

Anarinejad, A.; Reihanpour, M. (2015). Management and Planning in Multi-grade Classes, Shiraz: Shiva Rasa Publication.

Azizi, N.; Hossein Panahi, Kh. (2013). A Comparison of the Academic Achievement of the second-grade Students of Multi-grade Classrooms with those of Single-grade Classrooms in their Skills in the Persian Language, Scientific- Research Bi-quarterly of Shahed University, 20 $0^{\text {th }}$ year, NO. 3, autumn and Winter, p. 181.

Babadi Akasheh, Z.; Sharif, M.; Jamshidian, A. (2010). Providing and Extending Equal Opportunity and Educational Justice in Education in Isfahan, Journal of Social Welfare, $10^{\text {th }}$ year, NO. 37, p. 288.

Berry, C., (2001)." Achievement effects of multi-grade and mono-grade schools in the Turks and Caicaos Islands," International journal of education Development: Vol. 21(6), p 537-552. Childhood education. 71 (2), p102.

Compare: A Journal of Comparative and International Education, 38(4), pp. 505 -507.

Coskuna, K., Metinb, M., Bülbülc, K., \& Yõlmazd, G., (2011). "A study on developing an attitude scales towards multi-grade classrooms for elementary school teachers," WCES 201 Pericardial Social and Behavioral Science, p2734. free_management_ebooks.com, pp17-19.

Ghasemi, A. (2013). Investigating the Rate of Inequality of the Educational Opportunities in llam Province, Human Science Research, $4^{\text {th }}$ year, NO. 17, p. 101.

Haji Eshagh, S. (2004). The Teaching-learning Process in Multi-grade classes, Tehran: Korosh https://fa.wikipedia.org/wiki.

Hyry-Beihammera, E. K., Hascherb, T., (2015). "Multi-grade teaching practices in Austrian and Finnish Primary Schools," International Journal of Educational Research, P104.

Little, A .W.T., (2001). "Multi-grade Teaching towards International Research and Policy Agenda," International Journal of Educational Development, 21, pp. 481- 497.

Little, A., (2008)."Education for All and Multi-grade Teaching: Challenges and opportunities,"

Lockheed, M. ; Verspoor, A. (1992). The Quantitative Development and Qualitative Improvement of Primary Education in Developing Countries. Translated by Sajadieh, J. \& Alizadeh Hanji, H., Tehran: School Publication.

Mekosana, K.; Kapisa, M., Multi-grade teaching: introduction to multi-grade teaching, translated by Moharram Aghazadeh (2007), Ayizh Publication.

Molaei Harandi, F.; Jafari Harandi, H. (2012). Pathology of the Educational System of the Staff in Government Organizations. $2^{\text {nd }}$ National Conference of Pathology of Organizational Education with the Practical Approach Based on Executive Experiences in Organizations, p.1.

Moosaei, M.; Ahmadzadeh, M. (2009). Developmental Teaching and Sustainable Development, Journal of Development Strategy, NO. 18 , pp. 209-10.

Mortazavizadeh, H. (2015). Managing and Planning the Multi-grade Classes, Tehran: Korosh Publication. Pakistan," International Journal of Business and Social Science. 15(2), p170

Peirovi Cheshnaser, Sh.; Peirovi Cheshnaser, M.; (2015). The Barriers and Problems of the Multi-grade Classes of Primary Schools, p. 7. Publication.

Rafati, M., Khavari, A.; Sahebekhtiari, B. ; Aghamohammad, M. (2014). Identifying the Barriers and Executive Problems of Descriptive Qualitative Evaluation in Multi-grade mixed-sex Primary Schools, 1rd Scientific research Conference on Psychology, Educational Sciences and Pathology of the Society.

Rahim Bag, N. S., (2011)." The Possibilities and Challenges of Multi-grade Teaching in Rural 
Remello, P. A., (2003)" Multi grade schools in context: literary in the community, the home and the school in the Peruvian Amazon Patricia,"INSTITUTE OF EDUCATION, PhD THESIS December, p.19.

Samadian, S. (2006). How to Manage and Teach in Multi-grade Classes, Tehran: Moalef Publication.

Smith, R., Beihammer, E. K. H., Raggl, A., (2015). "Teaching and learning in small, rural schools in for European countries: I introduction and synthesis of mixed/multi_age approaches," P5 International of Journal of educational research.

Stone, S.J (1994)." Teaching strategist: Strategies for teaching children in multi age classroom,"

Taherizadeh, S.; Mosapour, N. (2014). Multi-grade Classes, the Neglected Aspect of the National Curriculum, $1^{\text {st }}$ National Conference of Sustainable Development in Educational Sciences and Psychology, Social and Cultural Studies, p.8.

Team FME (2013)." SWOT Analysis strategy skills," Team FME-WWW.

The Free Encyclopedia of Wikipedia, extracted in 30/10/2015. What is SWOT Analysis?

United Nations Educational, Scientific and Cultural Organization, France and UNESCO Bangkok Office (2015). Practical Tips for Teaching Multi-grade Classes, P3.

Wallace, J.; Mathot, G. (2005). A handbook for Teachers of Multi-grade Classes, translated by Ali Zarafshan, School Publication, Tehran.

Zahedi, Sh.; Najafi, Gh. (2006). The Conceptual Extension of Sustainable Development, Management Research in Iran (Humanities Modares), NO. 49, pp. 49-50. 